\title{
IMPLEMENTASI AUGMENTED REALITY PADA MEDIA PROMOSI PERUMAHAN PATRALAND PLACE
}

\author{
Riza Ivanadi Padeka Putri ${ }^{1}$, Dyah Ayu Irawati ${ }^{2}$, Deddy Kusbianto Purwoko A. ${ }^{3}$ \\ ${ }^{1,2}$ Program Studi Teknik Informatika, Jurusan Teknik Elektro, ${ }^{3}$ Politeknik Negeri Malang \\ rizaivanadi@gmail.com ${ }^{1}$, dyah.ayu@polinema.ac.id ${ }^{2}$,deddy_kusbianto@polinema.ac.id ${ }^{3}$
}

\begin{abstract}
Abstrak
Perumahan Patraland Place merupakan proyek properti pertama di kota Malang yang mempunyai banyak nilai, diantaranya lokasi strategis, harga bersaing dan fasilitas lengkap. Saat ini Perumahan Patraland Place menggunakan brosur sebagai media promosi, namun hal tersebut dirasa kurang menarik dan membosankan. Media promosi adalah salah satu komponen penting untuk mempromosikan suatu produk kepada konsumen. Untuk membuat media promosi menjadi lebih menarik dan berbeda bagi konsumen, salah satu caranya adalah dengan menerapkan teknologi augmented reality. Augmented reality merupakan teknologi yang memungkinkan menggabungkan suatu objek 3-Dimensi (3D) ke lingkungan nyata secara langsung melalui sebuah kamera. Berdasarkan hal tersebut untuk mendukung media promosi Perumahan Patraland Place dibuatlah sebuah aplikasi yang menerapkan augmented reality untuk menunjang promosi sehingga lebih menarik. Konten aplikasi ini ditujukan kepada pengguna smartphone sistem operasi Android dan dari berbagai profesi pekerjaan. Fitur augmented reality ditampilkan dengan cara mengarahkan kamera ke arah pola pada brosur maka akan muncul denah perumahan dengan tampilan 3D dan terdapat button untuk menampilkan informasi dari masing-masing tipe rumah. Untuk menuju virtual tour terdapat button virtual untuk menjelajahi dalam rumah sehingga membantu tanpa harus datang ke lokasi.

3D modelling dibuat menggunakan Google SketchUp, Vuforia dan Unity 3D sebagai game engine dalam pembuatan augmented reality dan virtual tour yang kemudian di-build menjadi apk agar dapat dijalankan pada smartphone android. Aplikasi ini sudah diujicobakan pada beberapa pengguna smartpone. Berdasarkan hasil uji coba tersebut dapat disimpulkan bahwa aplikasi ini dinilai sangat menarik, desain aplikasi menarik serta informasi yang disajikan menarik.
\end{abstract}

Kata Kunci: perumahan, Android, Augmented Reality, Virtual Tour

\section{Pendahuluan}

Kebutuhan teknologi berkembang seiring dengan perkembangan zaman. Bermacam teknologi telah diciptakan untuk berbagai keperluan dan pada berbagai bidang ilmu. Terutama di dalam bidang informasi, edukasi, dan komunikasi. Adapun perkembangan ini menimbulkan dampak positif bagi para pemakai. Seperti para pemakai teknologi ini akan melek intelek, pemakai akan dapat terus mengetahui informasi, dan berbagai keuntungan lainnya bila teknologi ini digunakan secara benar.

Salah satu teknologi yang berkembang sekarang ini disebut dengan Augmented Reality atau disingkat dengan AR, yaitu realita yang ditambahkan ke suatu media dapat berupa kertas dan marker atau penanda melalui perangkatperangkat input tertentu. Teknologi ini tidak sepenuhnya menggantikan sebuah realitas, tapi media informasi dan promosi.

Perkembangan teknologi Augmented Reality saat ini telah memberikan banyak kontribusi ke dalam berbagai bidang. Bidang-bidang tersebut meliputi periklanan dan pemasaran, arsitektur dan konstruksi, hiburan, medis, militer, dan menambahkan (augment) sebuah atau beberapa benda-benda maya dalam bentuk 2 atau 3 dimensi ke dalam lingkungan nyata dan ditampilkan secara real time atau waktu yang sebenarnya.

Teknologi Augmented Reality ini berbeda dengan teknologi Virtual Reality yang telah dikenal sebelumnya. Jika Virtual Reality benarbenar mengacu pada penggabungan dari objek dunia nyata ke dunia maya atau virtual. Augmented Reality berarti kebalikan dari Virtual Reality berupa integrasi elemen-elemen digital yang ditambahkan ke dalam dunia nyata secara real time, interaktif, dan mengikuti keadaan lingkungan yang ada di dunia nyata. Salah satu penggunaan Augmented Reality adalah sebagai

perjalanan wisata (Aditya-2014). Salah satu dari implementasi Augmented Reality yang terdapat pada bidang properti perumahan, yaitu pemanfaatan Augmented Reality dipakai sebagai media promosi dan pengenalan produk. 
Pemanfaatan Augmented Reality dalam media promosi dan pengenalan produk dapat dijadikan momen yang tepat untuk meningkatkan ketertarikan konsumen, karena sifatnya yang interaktif. teknologi Augmented Reality ini dapat digunakan misalnya pada acara pameran properti perumahan atau dimanapun.

Dari gambaran di atas penulis ingin membuat aplikasi dengan menerapkan Teknologi Augmented Reality pada media promosi Perumahan Patra Land Place.

\section{Metode}

Metodologi yang digunakan dalam penelitian ini adalah mengacu pada metodologi yang dikemukakan oleh Cathie Sherwood dan Terry Rout yang terdapat pada jurnal "A Structured Methodology for Multimedia Product And Systems Development".

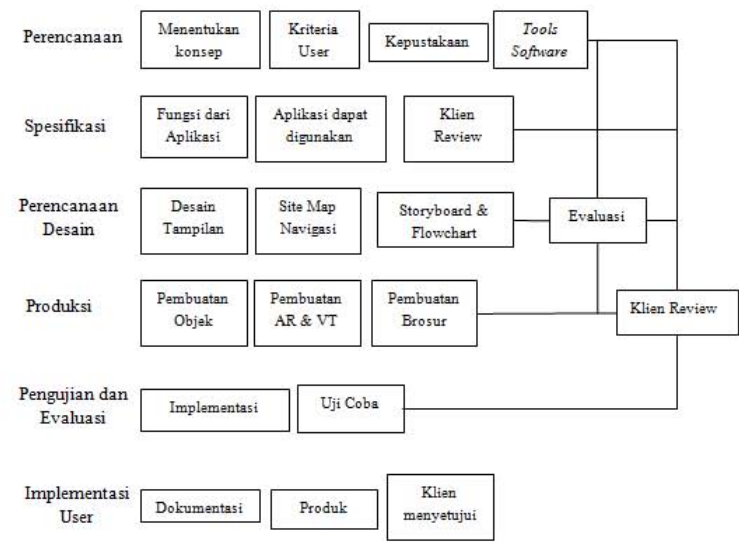

Gambar 2. 1 Metode Penelitian

\subsection{Perencanaan}

Pada tahap perencanaan diperlukan untuk pengembangan produk. Tahap ini mencakup penentuan strategi konsep secara keseluruhan, penguraian kriteria penerimaan klien, penelusuran informasi kepustakaan yang dibutuhkan hingga persiapan tools atau software yang akan digunakan dalam penelitian.

\subsection{Spesifikasi}

Pada tahap ini menampilkan keseluruhan rincian spesifikasi fungsional aplikasi yang akan dibangun. Spesifikasi fungsional dari aplikasi yang akan dibangun sebagai berikut:

a. Implementasi Augmented Reality dan Virtual Tour Perumahan Patraland Place Aplikasi Implementasi Augmented Reality pada media promosi perumahan Patraland Place nantinya pengguna dapat melihat langsung denah perumahan berupa 3D serta pengguna dapat berkeliling dalam rumah tipe 54 .

b. Berbasis android

Aplikasi yang akan dibuat berbasis android yang akan menampilkan denah perumahan Patraland Place serta pengguna dapat memilih untuk mengetahui informasi harga dan spesifikasi. Pengguna juga dapat memilih fitur virtual tour. Aplikasi ini memudahkan pengguna tanpa harus datang ke lokasi langsung.

\subsection{Perencanaan desain}

Pada tahap perencanaan desain, penulis membuat rancangan implementasi Augmented Reality pada media promosi perumahan Patraland Place yang akan digunakan pada aplikasi ini. Tujuannya untuk menghasilkan rancangan dengan konsep yang telah ditentukan. Berikut ini akan digambarkan proses-proses tersebut dalam bentuk bagan alur seperti yang terlihat pada gambar 2.1

\section{Rancangan Pemodelan Obyek 3D}

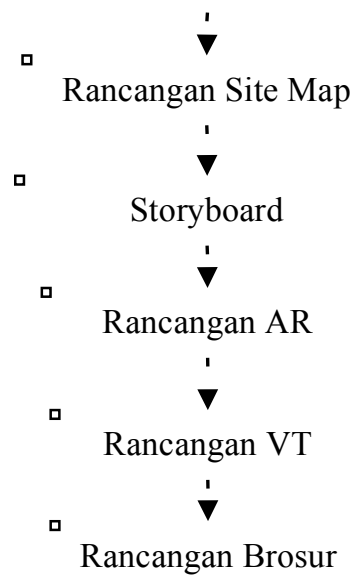

Gambar 2. 2 bagan alur perancangan

Perancangan aplikasi digambarkan melalui storyboard ringkas seperti tabel dibawah ini.

\begin{tabular}{|l|l|}
\hline Scene 1 & Merupakan menu utama \\
\hline Scene 2 & $\begin{array}{l}\text { Merupakan scene untuk } \\
\text { menampilan AR }\end{array}$ \\
\hline Scene 3 & $\begin{array}{l}\text { Merupakan scene untuk } \\
\text { menampilkan virtual tour }\end{array}$ \\
\hline Scene 4 & $\begin{array}{l}\text { Merupakan scene untuk } \\
\text { menampilkan option menu }\end{array}$ \\
\hline
\end{tabular}

Gambar 2. 3 Storyboard Ringkas

\subsection{Produksi}

Pada tahap ini seluruh pembuatan objek berdasarkan perancangan yang telah dibuat sebelumnya. Mula-mula buat rancangan objek 3 dimensi rancangan menu utama dengan site map selanjutnya pembuatan tampilan $\mathrm{AR}$ berupa denah perumahan dan pembuatan virtual Tour dengan story board, membuat rancangan desain 
brosur dengan bahan dari hasil pembuatan objek 3 dimensi.

\subsection{Pengujian dan Evaluasi}

Pada tahap ini dilakukan beberapa pengujian pada setiap tahap pembuatan aplikasi yang kemudian hasil pengujian menjadi bahan evaluasi.

\subsection{Implementasi pada user}

Pada tahap ini implementasi dilakukan pengujian aplikasi untuk mengetahui apakah aplikasi implementasi augmented reality pada media promosi dapat menimbulkan rasa ketertarikan sehingga menarik apabila media promosi diterapkan dengan menggunakan teknologi Augmented Reality.

\section{Hasil}

Dari hasil dari aplikasi Implementasi Augmented Reality pada Media Promosi Perumahan Patraland Place yang telah dibuat.

Berikut ini merupakan hasil dari rancangan desain brosur yang telah dibuat, dengan tampilan tampak depan pada gambar 3.2 dan tampak belakang 3.3

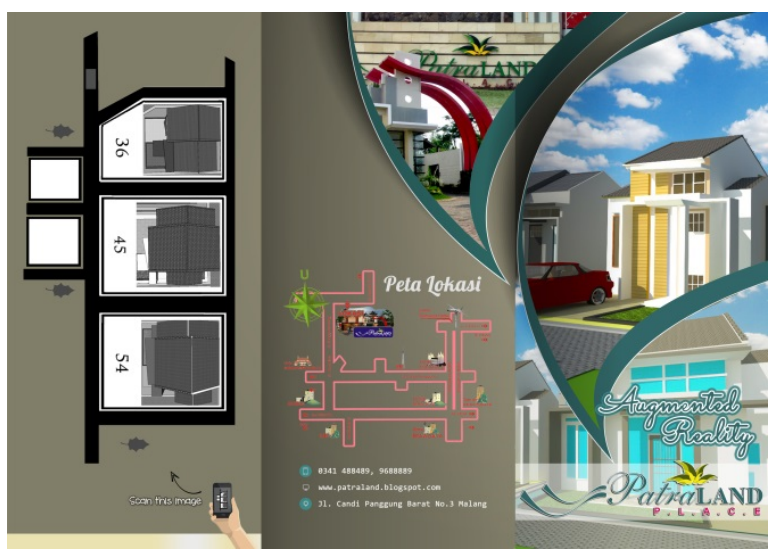

Gambar 3. 1 Hasil rancangan desain brosur tampak depan

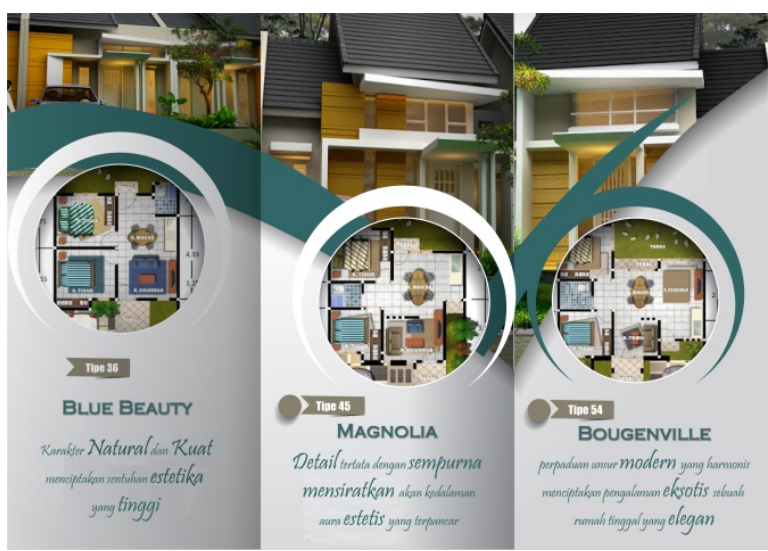

Gambar 3. 2 Hasil rancangan desain brosur tampak belakang
Berikut ini hasil Perancangan objek diantaranya yaitu, denah perumahan, rumah tipe 36, 45 dan 54.

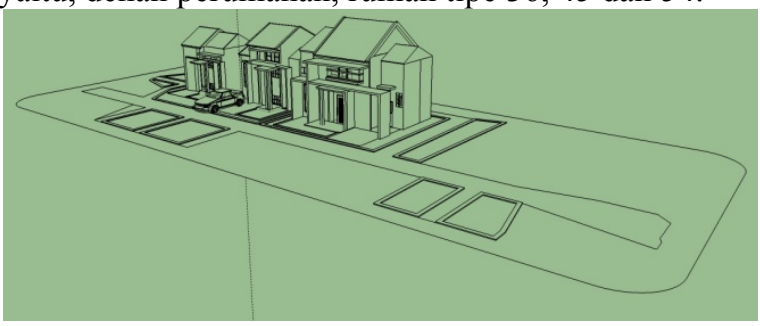

Gambar 3. 3 Hasil rancangan objek denah perumahan

Pengguna dapat mengakses aplikasi yang terinstall pada ponsel android, kemudian memilih menu ARCamera selanjutnya mengarahkan kamera kearah denah perumahan yang ada dalam brosur. Informasi tentang tipe rumah akan ditampilkan melalui layar ponsel android berupa teks.

Pada saat aplikasi dibuka akan muncul splashscreen dengan logo dari perumahan Patraland Place selama 4 detik, setelah itu akan muncul menu utama.

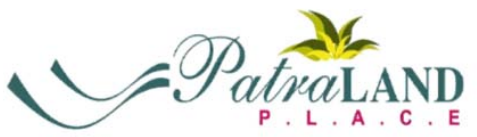

Gambar 3. 4 Gambaran Splashscreen

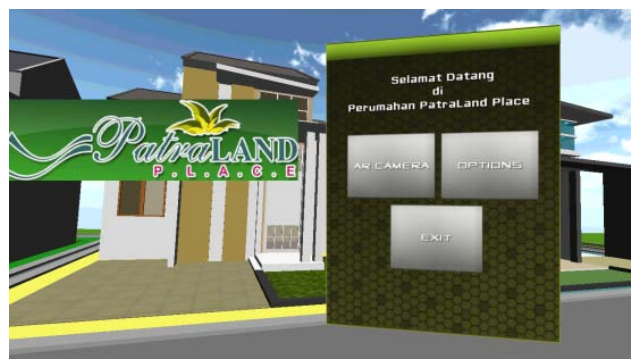

Gambar 3. 5 Aplikasi Main Menu ARPatraLand

Aplikasi ini juga dapat memunculkan informasi dengan menekan tombol yang berada di sisi bawah.

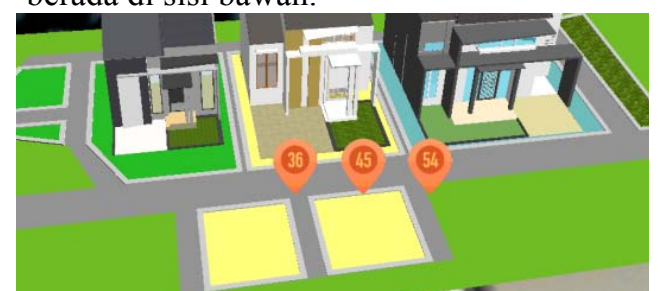

Gambar 3.6 Gambar tombol pada ARPatraLand 


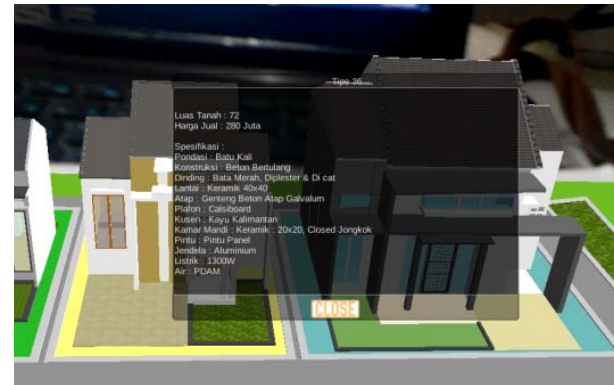

Gambar 3. 7 Gambar tampilan informasi

Pada tombol tipe rumah 54 akan muncul informasi dan terdapat tombol virtual untuk menuju ke virtual tour.

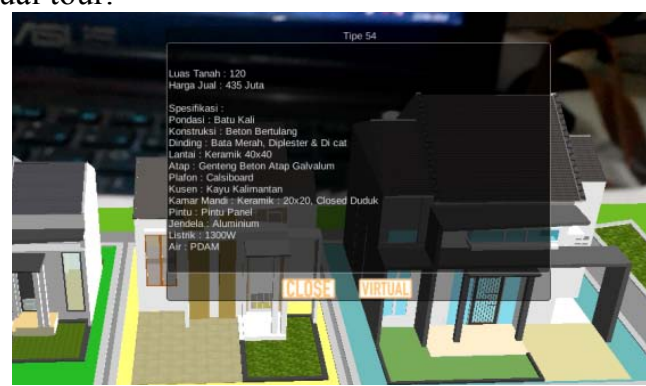

Gambar 3. 8 Gambar tombol ke virtual tour

Hasil rancangan tata ruang dapur, ruang tamu dan ruang makan dalam virtual tour rumah tipe 54 .

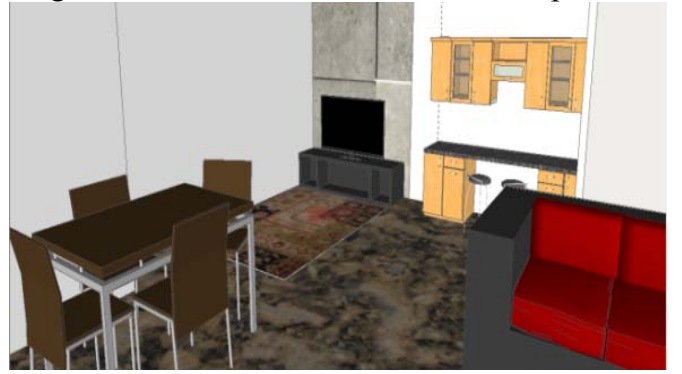

Gambar 3. 9 Hasil rancangan virtual tour yaitu rumah tipe 54

\section{Pembahasan}

Pada pembahasan akan membahas mengenai hasil dari aplikasi implementasi Augmented Reality pada media promosi perumahan patraland place.

Berdasarkan pengujian fungsional yang telah dilakukan melalui proses adaptasi teknologi media cetak ke dalam bentuk multimedia membutuhkan teknologi yang dapat memanipulasi grafis ke dalam bentuk digital dengan menggunakan perangkat agar dapat disampaikan atau ditayangkan dan dikontrol secara interaktif. Seperti pada gambar 3.2 dan 3.3 sebagai kondisi awal dapat ditransfer ke dalam media digital yang ditampilkan pada gambar 3.4

Dengan melakukan sinkrosinisasi data (teks dan grafis) secara terus menerus dalam bentuk tiga dimensi ke sebuah lingkungan nyata secara langsung atau real-time yang ditampilkan pada gambar 3.6, 3.7 dan 3.8.

Disamping itu untuk memperkenalkan bangunan yang menggabungkan teknologi grafis dengan teknologi informasi yang ditayangkan secara menyeluruh dalam bentuk 3 dimensi dan interaktif seperti yang ditampilkan pada gambar 3.9.

Berdasarkan pengujian kegunaan dilakukan dengan wawancara untuk mengungkap tingkat ketertarikan terhadap aplikasi ARPatraland 6 dari 8 responden pengguna smartphone kurang lebih 1 tahun (akrab android) cenderung menyatakan "Sangat Menarik" dengan adanya ARPatraland pada media promosi, 2 responden yang bukan akrab android cenderung "kurang menarik".

\section{Penutup}

a. Simpulan

Aplikasi Implementasi Augmented Reality pada media promosi Perumahan Patraland Place telah dapat menampilkan informasi sesuai dengan tujuan yang diinginkan. Aplikasi Implementasi Augmented Reality pada media promosi Perumahan Patraland Place ini lebih menarik dibandingkan brosur biasa karena dapat menggabungkan teknologi augmented reality dengan virtual tour sebagai media promosi. Akan tetapi aplikasi Implementasi Augmented Reality pada media promosi Perumahan Patraland Place bagi pengguna yang belum pernah memakai smartphone lebih memilih brosur biasa karena merasa belum akrab dengan touchscreen.

b. Saran

Adapun saran yang dapat dijadikan bahan pertimbangan oleh penulis yaitu aplikasi ini masih dapat dikembangkan lagi untuk memudahkan pengguna awam yang tidak terbiasa menggunakan android maka dapat dikembangkan ke berbasis dekstop.

\section{Daftar Rujukan}

[1] http://patraland.blogspot.com diakses pada tanggal 19 Juni 2014

[2] Binanto,Iwan. 2010. Multimedia Digital dasar Teori + Pengembanganya. Yogyakarta. ANDI .

[3] Fernando, Mario. 2013. Membuat Aplikasi Android Augmented Reality. Buku AR Online [4] http://iwanbinanto.com/2009/01/19/metodepengembangan-multimedia/ diakses tanggal 16 Juni 2014

[5] http://www.maxikom.co.id/gbshow.php?id=402 diakses tanggal 22 Juni 2014

[6] Arief Sadikin, Muhammad. 2012. Aplikasi Brosur Promosi Penjualan Apartemen centerpoint bekasi berbasis augmented reality. Universitas Gunadarma.

[7] Garsinia, Arif, Rengga. 2011. Virtual Tour PENS-ITS. Politeknik Elektronika Negeri Surabaya. [8] http://www.sketchup.com/about/sketchup-story diakses tanggal 16 Juni 2014 
[9] Mario, Sigit, Kusworo. 2013. Analisis Dan Perancangan Perangkat Lunak Pengenalan Motif Batik Berbasis Augmented Reality. Universitas Atma Jaya Yogyakarta.

[10]Sherwood, C. Dan Rout. 1998. "Structured Methodology For Multimedia Product And Systems Development". Australia: School of Computing and Information Technology, Griffith University.

[11] Andika, Diyan dan FoundaNico. 2012.

Pembuatan Virtual 3D Situs Sejarah Candi

Singosari Sebagai Media Informasi Wisata Sejarah. Politeknik Negeri Malang.

[12] Oktavianto, Fauzi dan Firman. 2012. Rancang Bangun Situs Sejarah Candi Jago Menggunakan Augmented Reality. Politeknik Negeri Malang. [13] Lang., Veronica, Sittler. Peter, 2012, Augmented Reality For Real Estate, 18th Annual Pacific-Rim Real Estate Society Conference Adelaide, Australia, 15-18 January 2012, 1-14. [14] Azuma, Ronald. [1997] A Survey Of Augmented Reality. Journal [Internet], pp. 1-52. Tersedia dalam : $<$ http://citeseerx.ist.psu.edu $>$, diakses 15 Juni 2014.

[15] Zaharuddin, G.Djalle. 2008. The Making of 3D animation movie using $3 D$ Studio Max. Bandung: Informatika.

[16] Santoso, Insap: Interaksi Manusia dan Komputer edisi 2, Penerbit ANDI Offset,2009. [17] Fahrul, Fadilah. 2013. Augmented Reality Untuk Mengetahui Fasilitas Umum Berbasis Android. PTIIK Universitas Brawijaya.

[18] http://patraland.blogspot.com/ diakses tanggal 2 Maret 2014

[19] Rizky, Aditya. 2014. Evaluasi Metode Pelacakan Tanpa Marker Pada Metaio Sdk Untuk Pengembangan Aplikasi Kuis Berbasis Augmented Reality Di Museum. Seminar Nasional Teknologi Informasi dan Multimedia Universitas Gajahmada. [20] http://www.scribd.com/doc/119759658/DefinisiPerumahan-Dan-Rumah diakses tanggal 2 April 2014

[21] Bendert., Katier. 2011. Mobile Augmented Reality. Master Thesis University of Amsterdam. [22] Simamarta, Janner. 2010. Rekayasa Perangkat Lunak. Yogyakarta . ANDI.

[23]http://www.android.com [24] Ardhi, Reza. 2011. Pembuatan Katalog Promosi Perumahan Pastika Condong Catur Residence Yogyakarta Dengan Augmented Reality. STMIK Amikom Yogyakarta. 